\title{
Superficial-Temporal-Artery-To-Middle-Cerebral-Artery Bypass in Cerebrovascular Occlusive Disease and Hemodynamic-Related Ischemia: Illustrative Case and Literature Review
}

\section{Bypass STA-MCA para doença cerebrovascular oclusiva e isquemia hemodinâmica: Caso ilustrativo e revisão da literatura}

\author{
Gustavo Rassier Isolan ${ }^{1}$ Ricardo de Andrade Caracante ${ }^{2}$ João Paulo Mota Telles ${ }^{2}$ \\ Nícollas Nunes Rabelo ${ }^{2}$ Eberval Gadelha Figueredo ${ }^{2}$
}

\author{
${ }^{1}$ Department of Neurosurgery, The Center for Advanced Neurology \\ and Neurosurgery (CEANNE), Porto Alegre, Brazil \\ 2 Department of Neurological Surgery, Faculdade de Medicina, \\ Universidade de São Paulo, São Paulo, Brazil
}

Address for correspondence Eberval Gadelha Figueiredo, MD, PhD, Faculdade de Medicina, Universidade de São Paulo, Av. Dr. Enéas de Carvalho Aguiar, 255, São Paulo, SP, Brazil (e-mail: ebgadelha@yahoo.com).

Arq Bras Neurocir 2021;40(2):e130-e136.

\author{
Abstract \\ Keywords \\ - extracranial- \\ intracranial bypass \\ - middle cerebral \\ artery \\ - superficial \\ temporal artery \\ - microvascular \\ anastomosis \\ - cerebrovascular \\ occlusive disease
}

Resumo
Stroke is the third most common cause of death worldwide. About $10 \%$ to $15 \%$ of strokes related to the territory of the carotid artery are associated with its complete occlusion. There is an important subgroup of patients with cerebrovascular occlusive diseases who might benefit from an external-carotid-to-internal-carotid bypass. In the present study, we report a case of a 53-year-old male patient with stenosis of the M2 branch of the middle cerebral artery (MCA), with a history of $\sim 20$ episodes of transient ischemic accidents (TIA)s, in whom an anastomosis of the M4 branch of the superficial temporal artery-MCA was performed. The patient was discharged in three days, and in the two years of follow-up, they were no more TIAs. We also conducted a review of the literature on cerebrovascular occlusive disease and extracranial-intracranial bypass surgery. New methods to evaluate cerebral hemodynamics made it possible to classify a new subgroup of patients with symptomatic cerebrovascular disease and documented cerebrovascular compromise in whom the drug therapy fails, who can benefit from the extracranial-intracranial bypass. Our case report illustrates the advantages of revascularization in these selected patients.

Acidentes vasculares cerebrais (AVC) são a terceira causa de mortalidade mundialmente. Entre 10 e 15\% dos AVCs relacionados à artéria carótida estão associados com sua oclusão completa. Há um subgrupo importante de pacientes com doenças cerebrovasculares oclusivas que podem se beneficiar de um by-pass carótida-externa-carótida-interna. Neste received

July 22,2020

accepted

September 25, 2020

published online January 18, 2021
DOI https://doi.org/ 10.1055/s-0040-1721335 ISSN $0103-5355$.

\footnotetext{
(c) 2021. Sociedade Brasileira de Neurocirurgia. All rights reserved. This is an open access article published by Thieme under the terms of the Creative Commons Attribution-NonDerivative-NonCommercial-License, permitting copying and reproduction so long as the original work is given appropriate credit. Contents may not be used for commercial purposes, or adapted, remixed, transformed or built upon. (https://creativecommons.org/ licenses/by-nc-nd/4.0/)

Thieme Revinter Publicações Ltda., Rua do Matoso 170, Rio de Janeiro, RJ, CEP 20270-135, Brazil
} 
estudo, reportamos o caso de um homem de 53 anos com estenose do ramo M2 da artéria cerebral média, com história de 20 acidentes isquêmicos transitórios (AIT), que foi tratado com anastomose de $\mathrm{M} 4$ com a artéria temporal superficial. O paciente foi de alta no terceiro dia pós-operatório e, em dois anos de follow-up, não houve mais AITs. Também conduzimos uma revisão da literatura sobre doença cerebrovascular oclusiva e by-pass intra-extracraniano. Novos métodos para avaliar a hemodinâmica cerebral tornaram possível a classificação de um novo subgrupo de pacientes com doença cerebrovascular sintomática em quem a terapia medicamentosa falhou, que podem se beneficiar de um by-pass intraextracraniano. Nosso relato de caso ilustra as vantagens de revascularização em pacientes selecionados.

\section{Introduction}

Stroke is the second most common cause of death around the world, according to World Health Organization (WHO). ${ }^{1}$ About $10 \%$ to $15 \%$ of strokes related to the territory of the carotid artery (CA) are associated with complete CA occlusion, which means, in the United States, an estimated 61 thousand patients with first-ever strokes, and 19 thousand patients every year with transient ischemic accidents (TIAs) associated with complete CA occlusion. ${ }^{2}$ With the advent of different diagnostic imaging methodologies that enable the study of cerebral hemodynamics, an important subgroup of patients has emerged. This cluster is composed of subjects in maximal medical therapy with hemodynamic compromise and symptomatic cerebrovascular occlusion disease ipsilateral to the occlusion. This group might benefit from externalCA-to-internal-CA bypass since their annual risk of stroke is $\sim 10 \%$ to $14 \%$ against $4 \%$ to $6 \%$ in those with preserved cerebral vasomotor reactivity. ${ }^{3,4}$ The present article aims to discuss the surgical approach in these cases through an illustrative case and a short review of the literature.

\section{Illustrative Case}

A 53-year old male was found to have a stenosis of the M2 segment of the middle cerebral artery (MCA) on cerebral angiography. His past medical history accounted for $\sim 20$ episodes of TIAs with right-sided facial-brachial hemiparesis and aphasia events. He also had controlled diabetes and hypertension, and was in dual-platelet anti-aggregation therapy. An anamostosis of the M4 branch of the superficial temporal artery (STA) was performed to increase the blood flow in the MCA territory. The patient was discharged in three days, and, in the two-year follow-up, there were no more TIAs. - Fig. 1 shows the pre- and postoperative arteriographies.

\section{Surgical Technique}

Under general anesthesia and intraoperative monitoring with an electroencephalogram and somatosensory evoked potentials, the patient is put in the supine position, with the head tilted to contralaterally to the craniotomy and fixed with the Mayfield three-point head holder. For patients with restriction of lateral neck rotation, a rolled blanket is put under the ipsilateral shoulder. The Doppler examination helps locate the branches of the STA on the scalp. Unless angiography or magnetic resonance angiography (MRA) shows a larger frontal branch, the posterior branch is chosen. The frontal branch must be used in cases of atresia of the parietal branch, previous craniotomy with a lesion to the parietal branch, or anterior-branch dominance.

An incision is made along the delineated course of the greater branch of the STA, extending from the preauricular region superiorly and then curved anteriorly. If the anterior branch is chosen, the surgeon must consider the fact that fibers of the superior division of the facial nerve can be crossing the region, and that this branch is anterior to the hairline. An

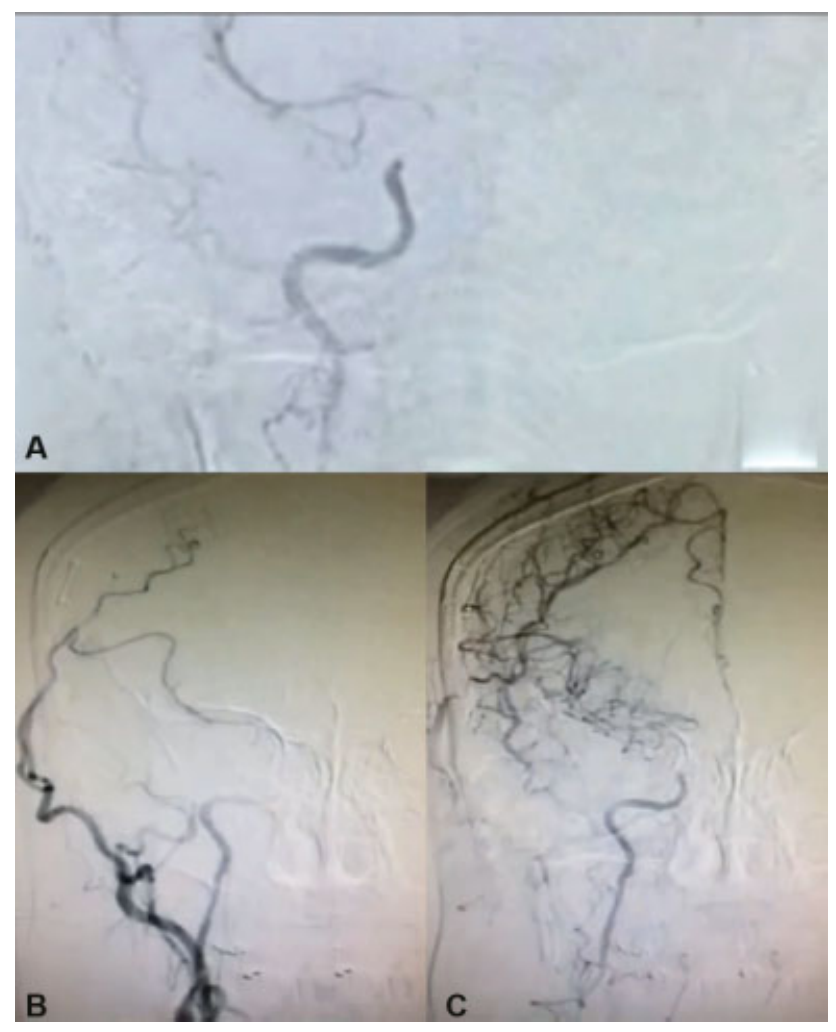

Fig. 1 Pre- and postoperative arteriography. (A) Preoperative arteriography showing significant occlusion of the internal carotid artery. (B and C) Postoperative arteriography showing significant reperfusion from the superficial temporal artery-middle cerebral artery (STA-MCA) bypass. 
option in such cases is direct dissection over the artery or "from the underside of the scalp flap distally". 5

After choosing the branch, the incision is deepened under magnification into the subcutaneous layer, where the STA branches run. Most commonly, the posterior branch is identified and followed to its origin using sharp dissection under microscope magnification. It is crucial to preserve the tissue adjacent to the vessel, except for the site used in the anastomosis (including the tip in which the adventitia is dissected) (-Fig. 2A).

Craniotomy is started by cutting the temporalis muscle, dissecting it with Bovie electrocautery, and fixing it with retractors. Following the exposure of the underlying bone, two burr holes are made, and the craniotomy is performed using a drill. Afterward, the dura is opened in a curvilinear fashion and tacked around the margins of the craniotomy to avoid postoperative epidural hematoma. The cortical branch of the MCA is chosen based mainly on the size of the vessel ( $\geq 1.5 \mathrm{~mm}$ is ideal). To facilitate the procedure, the site of anastomosis must be located far from the borders of the craniotomy, and the vessel must be oriented tangentially.

After establishing the cortical branch that will be used, attention is redirected to the STA. The tip of the artery is dissected and cut in a sharp fashion (-Fig. 2B). The surrounding fascia of the adventitia is stripped out only on the border side of the anastomosis. It is not recommended to dissect all of the vessel's extension because it is not helpful, and there is an increased risk of injury. A small microclip is placed proximally to the stump of the artery, which is then directed down into the level of the isolated cortical branch.

The anastomosis site of the STA is cut at a $45^{\circ}$ angle. The proximal clip is removed to check the free flow through the end of the vessel. Then, an arteriotomy is performed on the cortical branch using sharp microscissors. The edges of both sides of the anastomosis are marked with a marking pen to highlight the lumen. At this moment, the lumen of the STA must be inspected to observe the conditions of its margins.

Temporary clips are placed proximal and distal to the site of the anastomosis in the cortical vessel, which receives an incision with the same length as that of the STA diameter. Under further magnification using the microscope, the anastomosis is performed using 10-0 sutures, with approximately 6 interrupted sutures in an end-to-side fashion preceded by anchoring sutures. To reduce injury to the endothelium of the vessel, the suture is passed through the recipient vessel from the inside out (-Fig. 2C). Subsequently, the hemostatic clips are removed from both the proximal and distal aspects of the cortical vessels, and then the ones in the superficial temporal artery are also removed. A small piece of absorbable hemostat is wrapped around the anastomosis site ( - Fig. 2D). At this stage, papaverine is applied at the suture line for hemostasis (-Fig. $\mathbf{3}$ ).

The Doppler is used to confirm the patency of the STA branch, which must pulse along with the rest of the anastomosis. Currently, we are using the cut flow index for evaluation.

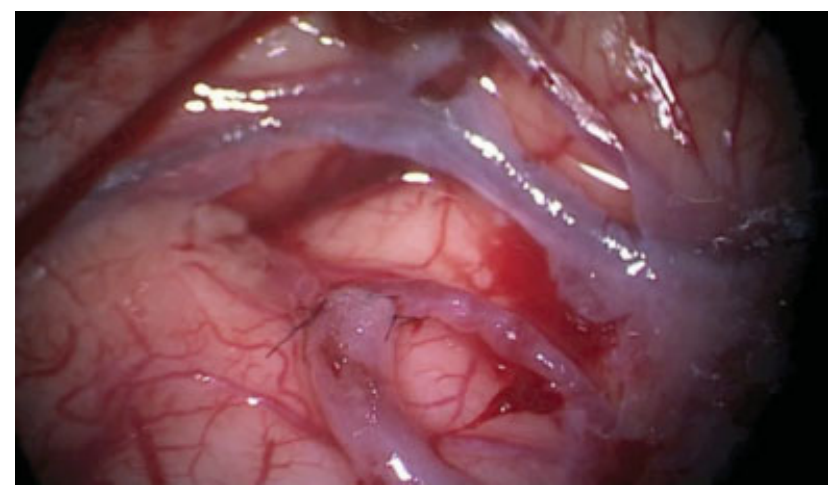

Fig. 3 Final aspect of the anastomosis: STA-MCA bypass.

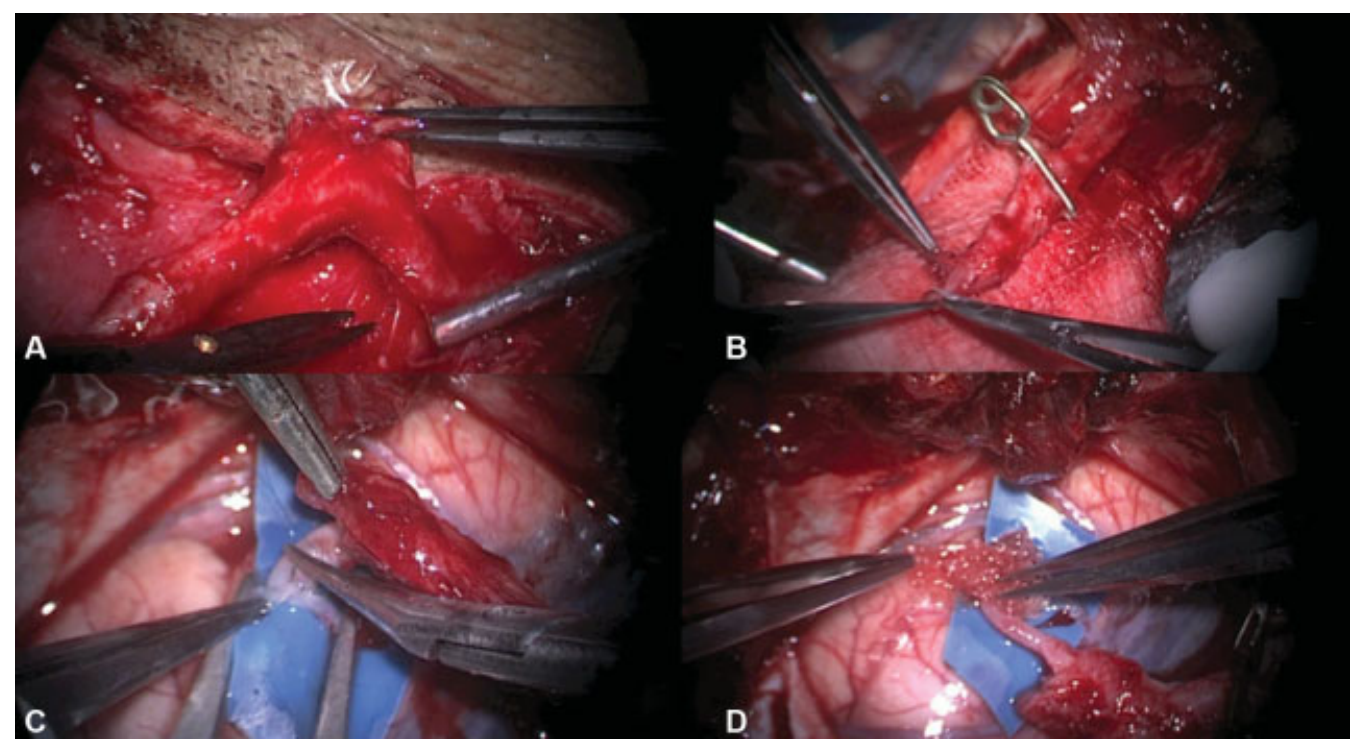

Fig. 2 Bypass preparation. (A) Dissection and preparation of the donor vessel, the STA. (B) Temporary clip placed in the STA. The vessel is then dissected and cut in a sharp fashion. The surrounding fascia of the adventitia is stripped out only in the border side of the anastomosis. (C) The anastomosis is performed using 10-0 sutures with around 6 interrupted sutures in an end-to-side fashion preceded by anchoring sutures. To reduce injury to the vessel's endothelium, the suture is passed through the recipient vessel from the inside out. (D) A small piece of absorbable hemostat is wrapped around the anastomosis site. At this stage, papaverine is applied at the suture line for hemostasis. 
Closure begins by approximating the dura and applying Gelfoam (Upjohn, Kalamazoo, MI, US) to the epidural space. The bone flap is trimmed to allow a window for the entrance of the STA into the intracranial cavity. The bone is placed in position and held in place using miniplates. The temporal muscle is then approximated loosely without constriction around the pedicle of the STA. To optimize flow through the anastomosis, the unused branch of the STA is ligated. The scalp is closed using 2-0 Vicryl (Ethicon, Somerville, NJ, US) in an interrupted inverted fashion, approximating the subcutaneous tissue to the galea.

\section{Literature Review}

\section{Historical Background}

Nicholls et al. ${ }^{6}$ concluded that unilateral CA occlusions are mainly associated with cases of ipsilateral strokes (25\%) and ipsilateral TIAs (16\%). Cote et al. ${ }^{7}$ reported that, over 34 months, patients with occlusion of the internal carotid artery (ICA) with no or mild neurological deficit have an overall stroke risk of $15 \%$ - similar to that of patients suffering from TIAs or minor strokes -, and $63 \%$ of these strokes were ipsilateral to the occlusion. In patients with CA occlusion and contralateral stenosis, Hammacher et al. ${ }^{8}$ documented a rate of stroke of $33 \%$ to $40 \%$ per year. For those patients with symptomatic CA occlusion confirmed angiographically, a 5.9\% yearly risk of ipsilateral stroke was described by Hankey and Warlow. ${ }^{9}$

Professor M. Gazi Yaşargil, ${ }^{10}$ a pioneer in cerebrovascular anastomosis, started to perform this procedure in dogs, and later published his results on human patients. ${ }^{11,12}$ The technique was widely propagated, but there was no proof of the procedure's efficacy in preventing new strokes.

In the 1980s, the EC/IC Bypass Study Group ${ }^{13}$ also failed to confirm whether the surgery was effective in preventing ischemic events in patients with atherosclerotic arterial disease in the CA or MCA territory. After that, extracranialintracranial (EC-IC) bypass has been restricted for cases of moyamoya disease and patients who need ICA occlusion due to an unclipplable aneurysm or skull-base tumor.

Nonetheless, at the time when both studies were conducted, there was no physiological knowledge or a reliable and proven method to identify crucial hemodynamic factors that would enable the stratification of patients according to the risk of new ischemic events, ${ }^{2,14-16}$ thus detecting a subgroup of patients that could benefit from the revascularization procedure.

Grubb Jr. et al., ${ }^{17}$ in the St Louis Carotid Occlusion Study (STLCOS), established that such subgroups could be identified through indirect assessments based on the brain's compensatory mechanisms regarding progressive reductions in cerebral-perfusion pressure (CPP). In the same study, ${ }^{17}$ the authors also concluded that those patients with symptomatic CA occlusion and stage-II hemodynamic failure (decreased cerebral blood flow [CBF] with increased oxygen extraction fraction $[\mathrm{OEF}]$ ) who were medically treated were at a higher risk for subsequent stroke.

\section{Current Perspective}

It is currently well known that a decreased CBF is generally unhelpful to detect the risk of future stroke because it cannot distinguish whether the cause of this reduction is an occlusive event or a compensatory physiological response due to reduced metabolic demands. ${ }^{17}$

On the other hand, the accuracy increases if activated studies are used, which means obtaining an initial measurement at rest and another after provision of a cerebral vasodilatory stimulus (with acetazolamide, hypercapnia, or physiological tasks). A reduced responsiveness of the $\mathrm{CBF}$ to these stimuli means that the capacity for compensatory vasodilation is exceeded, and there is an impaired cerebral vasomotor reactivity to the diminished CPP.

There are different methods to measure the cerebrovascular reactivity (CVR) indices, and thus estimate the risk of stroke, such as xenon computed tomography (XeCT) with and without acetazolamide, ${ }^{18}$ positron-emission tomography (PET), ${ }^{19,20}$ and transcranial Doppler flowmetry, ${ }^{21}$ which is much less sensitive than XeCT. ${ }^{22}$

In subsequent series, Nussbaum and Erickson ${ }^{23}$ were able to show improvement in patients with symptomatic cerebrovascular disease refractory to medical treatment submitted to EC-IC bypass surgery, and Charbel et al. ${ }^{5}$ reported that careful attention to the technique could result in consistent success.

\section{Recent Advances}

Two recent multicentric randomized trials tried to validate the use of EC-IC anastomosis: the Carotid Occlusion Surgery Study (COSS), ${ }^{29}$ in the United States, and the Japanese Extracranial to Intracranial Bypass Trial (JET). ${ }^{30}$ The latter tested patients with $\mathrm{XeCT}, \mathrm{PET}$, or single-photon emission computed tomography (SPECT), while the former tested with PET.

The COSS was halted due to futility. The perioperative ipsilateral stroke rates were higher in the surgical group compared with the medical group. Moreover, the study concluded that the surgical treatment, in the selected patients, was not of clinical benefit. Still, later publications $^{24}$ showed that in two years the surgical group achieved high rates of bypass graft patency, improved cerebral hemodynamics, and much lower rates of recurrent ipsilateral ischemic stroke after the second postoperative day compared with medical group. ${ }^{25}$ In a subsequent paper, the authors concluded that the majority of ischemic strokes that occurred in the postoperative period were not related to the bypass grafting but to hemodynamic fragility of the study population. $^{26}$

The COSS was received with some criticism, primarily related to: 1) the unexpected low rate of stroke in the medical group $^{27,28} ; 2$ ) its semiquantitative method to measure the OEF ratio, which was different from the quantitative method applied in the STLCOS $27,29-31 ;$ and 3) its clinical selection criteria, which included patients with a single ischemic event or those relatively neurologically stable. ${ }^{27,28,32}$

Nearly all of the ctiticismswere addressed by Powers et. al. ${ }^{33}$ Still, as Esposito et al. ${ }^{32}$ highlight that there are factors regarding the perioperative stroke rates that should have been debated, such as the lack of an established perioperative protocol for the COSS, or the recruitment requirements of the other health professionals involved in the study. 


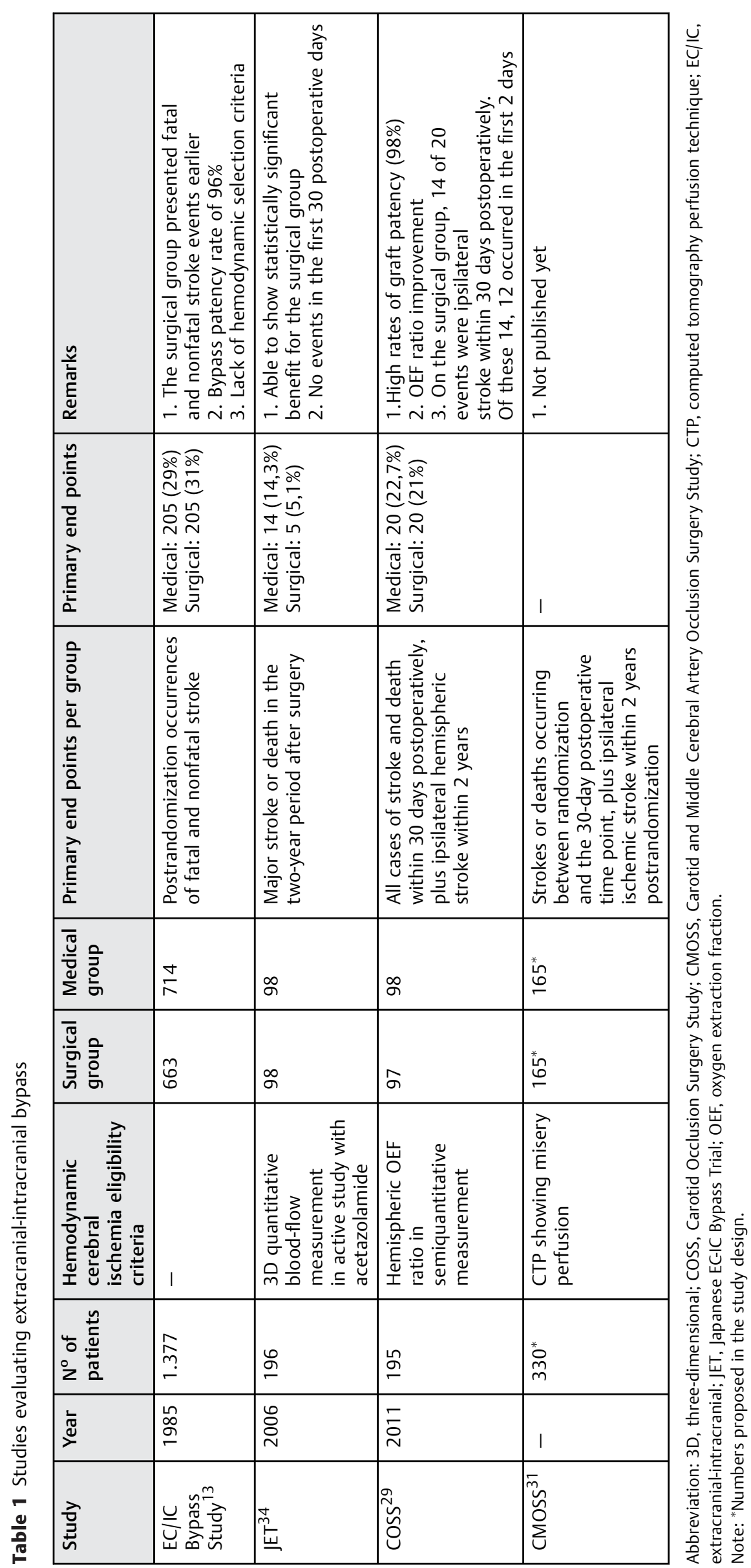


In contrast, the JET Study, ${ }^{34}$ in a second interim analysis, affirmed that the surgically-treated group presented a lower incidence of stroke recurrence compared with those who had only been submitted to medical therapy. Nevertheless, in the published Kaplan-Meier curve, there were no deaths within the first month in the surgical group - which seems unlikely to occur, given that the perioperative morbidity and mortality rate was of $12 \%$ in the EC-IC Bypass Trial, and of $15 \%$ in the coss. ${ }^{25,32,35}$

Later, a multicentric prospective cohort, the JET-2 Study, ${ }^{30}$ compared a total of 132 enrolled patients with symptomatic cerebrovascular occlusive disease and mild-to-moderate hemodynamic impairment with the medical arm group of the JET Study. The objective was to determine the real threshold of CBF and CVR for subsequent ischemic events only among the medically-treated patients. The authors found that patients with rest $\mathrm{CBF}>80 \%$ or $\mathrm{CVR}>10 \%$ present a lower risk, and they thus concluded that this population is unlikely to benefit from the EC-IC bypass surgery.

Due to all the controversial results and doubts surrounding the latest studies, there are still questions concerning this subject. Therefore, another trial ${ }^{31}$ is being conducted in China under registration code NCT01758614. All the aforementioned trials were synthesized in -Table 1.

\section{Assessing Bypass Function}

Regarding the technique, there are several ways to assess bypass function transoperatively, such as observing the pulsations within the donor vessel subsequently to the anastomosis, intraoperative microvascular Doppler sonography, and intraoperative angiography. The observation is inaccurate, for it is highly subjective. The Doppler enables us to properly evaluate the site of anastomosis. However, the intraoperative angiography assessment of graft patency can increase the success of the EC-IC bypass not only because it enables physicians to assess the site of anastomosis but also the extent of reperfusion from the bypass.

Yanaka et al. ${ }^{36}$ assessed the intraoperative angiography method in 42 STA-MCA bypass procedures. The imaging findings prompted two additional procedures, and there were no complications. However, there was no systematic comparison with an ultrasonography method.

Therefore, until a large clinical study compares, in longterm follow-up, both methods and proves superior results for angiography, we do not recommend such a procedure, because, while sonography is a rapid, noninvasive, sensitive, and easily performed method, cerebral angiography is a time-consuming, invasive procedure with cost-benefit limitations. Microvascular Doppler sonography, however, does not distinguish between a poor and a robust flow in the anastomosis.

Currently, a quick and straightforward method to predict graft success after EC-IC bypass is the cut flow index, through which a quantitative assessment of graft patency may be performed. This approach was a significant predictor of bypass patency in 51 review retrospective cases of EC-IC anastomosis. ${ }^{37}$ Although our rates of patency had an excellent correlation with the Doppler sonography, we must consider that the cut flow index is a very reasonable method, and we have recently started to use it.

Concerning flap necrosis, Katsuta et al. ${ }^{38}$ studied the relationship between cutaneous necrosis after STA-MCA bypass and surgical methods or risk factors. The authors found that postoperative necrosis and arteriosclerosis obliterans were related. In a univariate analysis, smoking was a statistically significant risk factor - but not in a multivariate analysis. All seven patients with necrosis were treated with the flap method. They concluded that: 1) arteriosclerosis obliterans in the lower extremities is probably the best predictor of postoperative cutaneous necrosis; 2) the cutdown method may be preferable in patients with arteriosclerosis obliterans or smokers. In the Katsuta et al. ${ }^{38}$ series, one patient developed scalp necrosis.

Finally, microsurgical laboratory training is paramount. A technically-perfected microanastomosis begins in the microsurgical laboratory. The neurosurgeon who wishes to perform this procedure must understand that this is the first and most crucial step for the future outcome of their patients. The continuous exercises in vessels of the placenta and later in vessels of rats will indicate essential aspects to pay attention to, such as unwilling suture of the anterior and posterior wall of the vessel, traumatic lesion of the vessel that can be avoided by careful manipulation of the adventitia, asymmetry of the suture's borders, inappropriate tension of the suture, and others. ${ }^{39}$ The surgeon will become apt only with hard training in the laboratory. Professor Yaşargil ${ }^{10}$ recommended training anastomosis in the laboratory for at least three months.

\section{Conclusion}

The exact parameters to indicate the STA-MCA bypass in cerebrovascular occlusive disease have not been established yet. First, because the population addressed in the recent trials seems to be comprised of patients with a more stable neurological condition. Second, because these studies point to different results. Lastly, they were criticized due to possible methodological flaws. Therefore, there is still controversy about the indications and benefits of EC-IC bypass surgery, which could be elucidated by ongoing trials. As illustrated by our case, selected patients could significantly benefit from this approach

\section{Conflict of Interests}

The authors have no conflict of interests to declare.

\section{References}

1 World Health Organization Global Health Estimates 2018: Disease burden by Cause, Sex, by Country and Region, 2000-2016 World Heal. Organ. 2018:22-24

2 Grubb RL Jr, Powers WJ, Derdeyn CP, Adams HP Jr, Clarke WR. The Carotid Occlusion Surgery Study. Neurosurg Focus 2003;14(03):e9

3 Klijn CJ, Kappelle LJ, Tulleken CA, van Gijn J. Symptomatic carotid artery occlusion. A reappraisal of hemodynamic factors. Stroke 1997;28(10):2084-2093. Doi: 10.1161/01.str.28.10.2084

4 Vernieri F, Pasqualetti P, Passarelli F, Rossini PM, Silvestrini M. Outcome of carotid artery occlusion is predicted by cerebrovascular reactivity. Stroke 1999;30(03):593-598. Doi: 10.1161/01. STR.30.3.593 
5 Charbel FT, Meglio G, Amin-Hanjani S. Superficial temporal artery-to-middle cerebral artery bypass. Neurosurgery 2005;56 (1, Suppl):186-190, discussion 186-190. Doi: 10.1227/01. NEU.0000144487.85531.FD

6 Nicholls SC, Bergelin R, Strandness DE. Neurologic sequelae of unilateral carotid artery occlusion: immediate and late. J Vasc Surg 1989;10(05):542-547, discussion 547-548. Doi: 10.1067/ mva.1989.15723

7 Cote R, BarnettHJ, Taylor DW. Internal carotid occlusion: a prospective study. Stroke 1983;14(06):898-902. Doi: 10.1161/01.str.14.6.898

8 Hammacher ER, Eikelboom BC, Bast TJ, De Geest R, Vermeulen FE. Surgical treatment of patients with a carotid artery occlusion and a contralateral stenosis. J Cardiovasc Surg (Torino) 1984;25(06):513-517

9 Hankey G, Warlow C. Prognosis of symptomatic carotid artery occlusion. Cerebrovasc Dis 1991;1:245-256. Doi: 10.1159/000108851

10 Yaşargil MG. A legacy of microneurosurgery: memoirs, lessons, and axioms. Neurosurgery 1999;45(05):1025-1092. Doi: 10.1097/00006123-199911000-00014

11 Yasargil M. Anastomosis between the superficial temporal artery and a branch of the middle cerebral artery. In: Yasargil MG, ed. Microsurgery applied to neurosurgery. Stultgart Georg Thieme 1969:105-115

12 Yasargil MG, Yonekawa Y. Results of microsurgical extra-intracranial arterial bypass in the treatment of cerebral ischemia. Neurosurgery 1977;1(01):22-24. Doi: 10.1227/00006123-197707000-00005

13 EC/IC Bypass Study Group. Failure of extracranial-intracranial arterial bypass to reduce the risk of ischemic stroke. Results of an international randomized trial. N Engl J Med 1985;313(19): 1191-1200. Doi: 10.1056/NEJM198511073131904

14 Sundt TM Jr. Was the international randomized trial of extracranial-intracranial arterial bypass representative of the population at risk? N Engl J Med 1987;316(13):814-816. Doi: 10.1056/ NEJM198703263161318

15 Awad IA, Spetzler RF. Extracranial-intracranial bypass surgery: a critical analysis in light of the International Cooperative Study. Neurosurgery 1986;19(04):655-664

16 Kirkpatrick PJNI, Ng I. Cerebral revascularisation: where are we now? J Neurol Neurosurg Psychiatry 2005;76(04):463-465. Doi: 10.1136/jnnp.2004.035998

17 Grubb RL Jr, Derdeyn CP, Fritsch SM, et al. Importance of hemodynamic factors in the prognosis of symptomatic carotid occlusion. JAMA 1998;280(12):1055-1060. Doi: 10.1001/jama.280.12.1055

18 Yonas H, Smith HA, Durham SR, Pentheny SL, Johnson DW. Increased stroke risk predicted by compromised cerebral blood flow reactivity. J Neurosurg 1993;79(04):483-489. Doi: 10.3171/ jns.1993.79.4.0483

19 Derdeyn CP, Videen TO, Simmons NR, et al. Count-based PET method for predicting ischemic stroke in patients with symptomatic carotid arterial occlusion. Radiology 1999;212(02): 499-506. Doi: 10.1148/radiology.212.2.r99au27499

20 Yamauchi H, Fukuyama H, Nagahama Y, et al. Significance of increased oxygen extraction fraction in five-year prognosis of major cerebral arterial occlusive diseases. J Nucl Med 1999;40 (12):1992-1998

21 Kleiser B, Widder B. Course of carotid artery occlusions with impaired cerebrovascular reactivity. Stroke 1992;23(02):171-174. Doi: 10.1161/01.str.23.2.171

22 Pindzola RR, Balzer JR, Nemoto EM, Goldstein S, Yonas H. Cerebrovascular reserve in patients with carotid occlusive disease assessed by stable xenon-enhanced ct cerebral blood flow and transcranial Doppler. Stroke 2001;32(08):1811-1817. Doi: 10.1161/01.str.32.8.1811

23 Nussbaum ES, Erickson DL. Extracranial-intracranial bypass for ischemic cerebrovascular disease refractory to maximal medical therapy. Neurosurgery 2000;46(01):37-42, discussion 42-43. Doi: 10.1097/00006123-200001000-00008
24 Grubb RL Jr, Powers WJ, Clarke WR, Videen TO, Adams HP Jr, Derdeyn CPCarotid Occlusion Surgery Study Investigators. Surgical results of the carotid occlusion surgery study: Clinical article. J Neurosurg 2013;118(01):25-33. Doi: 10.3171/2012.9.JNS12551

25 Reynolds MR, Derdeyn CP, Grubb RL Jr, Powers WJ, Zipfel GJ. Extracranial-intracranial bypass for ischemic cerebrovascular disease: what have we learned from the Carotid Occlusion Surgery Study? Neurosurg Focus 2014;36(01):E9. Doi: 10.3171/ 2013.10.FOCUS13427

26 Reynolds MR, Grubb RL Jr, Clarke WR, et al; Carotid Occlusion Surgery Study Investigators. Investigating the mechanisms of perioperative ischemic stroke in the Carotid Occlusion Surgery Study. J Neurosurg 2013;119(04):988-995. Doi: 10.3171/2013.6. JNS13312

27 Amin-Hanjani S, Barker FG II, Charbel FT, Connolly ES Jr, Morcos JJ Thompson BGCerebrovascular Section of the American Association of Neurological Surgeons Congress of Neurological Surgeons. Extracranial-intracranial bypass for stroke-is this the end of the line or a bump in the road? Neurosurgery 2012;71(03):557-561. Doi: 10.1227/NEU.0b013e3182621488

28 Heros RC. Carotid occlusion. J Neurosurg 2013;118(01):20-22, discussion 22-24. Doi: 10.3171/2012.6.jns121106

29 Carlson AP, Yonas H, Chang YF, Nemoto EM. Failure of cerebral hemodynamic selection in general or of specific positron emission tomography methodology?: Carotid Occlusion Surgery Study (COSS) Stroke 2011;42(12):3637-3639. Doi: 10.1161/STROKEAHA.111.627745

30 Kataoka H, Miyamoto S, Ogasawara K, et al; JET-2 Investigators. Results of prospective cohort study on symptomatic cerebrovascular occlusive disease showing mild hemodynamic compromise. [Japanese extracranial-intracranial bypass trial (Jet)-2 study] Neurol Med Chir (Tokyo) 2015;55(06):460-468. Doi: 10.2176/ nmc.oa.2014-0424

31 Ma Y, Gu Y, Tong X, et al. The Carotid and Middle cerebral artery Occlusion Surgery Study (CMOSS): a study protocol for a randomised controlled trial. Trials 2016;17(01):544. Doi: 10.1186/s13063016-1600-1

32 Esposito G, Amin-Hanjani S, Regli L. Role of and indications for bypass surgery after Carotid Occlusion Surgery Study (COSS)? Stroke 2016;47(01):282-290. Doi: 10.1161/STROKEAHA.115.008220

33 Powers WJ, Clarke WR, Adams HP Jr, Derdeyn CP, Grubb RL Jr. Commentary: Extracranial-intracranial bypass for stroke in 2012: response to the critique of the carotid occlusion surgery study "It was déjà vu all over again". Neurosurgery 2012;71(03):E772-E776. Doi: 10.1227/NEU.0b013e318268c7d3

34 Ogawa A. Japanese EC-IC Bypass Trial (JET Study): the interim analysis. Nosotchu 2003;25(04):397-400. Doi: 10.3995/jstroke.25.397

35 Powers WJ. Management of patients with atherosclerotic carotid occlusion. Curr Treat Options Neurol 2011;13(06):608-615

36 Yanaka K, Fujita K, Noguchi S, et al. Intraoperative angiographic assessment of graft patency during extracranial-intracranial bypass procedures. Neurol Med Chir (Tokyo) 2003;43(10):509-512, discussion 513. Doi: 10.2176/nmc.43.509

37 Amin-Hanjani S, Du X, Mlinarevich N, Meglio G, Zhao M, Charbel FT. The cut flow index: an intraoperative predictor of the success of extracranial-intracranial bypass for occlusive cerebrovascular disease. Neurosurgery 2005;56(1, Suppl):75-85, discussion 7585. Doi: 10.1227/01.NEU.0000143032.35416.41

38 Katsuta T, Inoue T, Arakawa S, Uda K. Cutaneous necrosis after superficial temporal artery-to-middle cerebral artery anastomosis: is it predictable or avoidable? Neurosurgery 2001;49(04):879-882, discussion 882-884. Doi: 10.1227/00006123-200110000-00019

39 Isolan GR, Brolin SIPM, Dobrowolski S, Giotti M. Considerações Técnicas no Treinamento de Anastomoses Microvasculares em Laboratório de Microcirurgia. J Bras Neurocir 2018;21(01):8-17 